\title{
Factors Contributing to Late Physiotherapy Intervention of Children with Cerebral Palsy at The University Teaching Hospital, Lusaka in Zambia
}

\author{
Chona Kanyembo ${ }^{1}$, Geoffrey Moyo ${ }^{1}$, Brian Chanda Chiluba ${ }^{2^{\star}}$ \\ ${ }^{1}$ Department of Physiotherapy, School of Health Sciences, The University of Zambia. \\ ${ }^{2}$ Research unit, School of Health Sciences, The University of Zambia
}

\begin{abstract}
Cerebral palsy is the leading cause of disability worldwide and Zambia has its fair share of cases. Most parents/caregivers of children with Cerebral palsy at University Teaching Hospital started attending physiotherapy late when their children were over one year. Therefore, the aim of this study was to explore the perceptions of mothers towards factors contributing to late physiotherapy intervention of children with Cerebral palsy at University Teaching Hospital. Furthermore, assess the knowledge of mothers with children between 0-5 years on the role of physiotherapy in Cerebral palsy. Methodology: An exploratory study design using qualitative methods was used. Data collection techniques were Focus group discussions that consisted of purposively sampling of 10 mothers of children with Cerebral palsy attending physiotherapy at University Teaching Hospital. Audio-recording from the focus group discussions was transcribed verbatim for each session by an independent person. The study employed thematic analysis for data analysis. The data was classified systematically by means of coding to identify key factors or issues such as concepts, categories, themes and the relationship between them. Results: This study identified four themes on factors that influence late physiotherapy intervention of children with Cerebral Palsy at University Teaching Hospital. These included: Socio-economic support; late referral for Physiotherapy; Caregiver's knowledge about Cerebral Palsy; and People's attitude towards Cerebral Palsy. Limited caregiver knowledge about the role of physiotherapy in Cerebral Palsy was reported to be due to; limited community awareness about physiotherapy; and lack of caregiver education. Conclusion: The present study sought to explore the perceptions of mothers towards factors contributing to late physiotherapy intervention in children with Cerebral Palsy. A diversity of factors that led to delayed intervention was highlighted. Rehabilitation professionals should be aware of the factors that impact mothers both positively and negatively in order to implement effective rehabilitation programs.
\end{abstract}

Keywords: Cerebral palsy, Physiotherapy Intervention, Rehabilitation

\section{Research Background}

Brenhaut et al., (2004) states that, caring for CP children sometimes presents a negative effect on the wellbeing of caregivers, which can take the form of emotional problems, depression, distress, low self-esteem and chronic sorrow. Cerebral palsy is a 
sudden event and parents/caregivers are forced to accept a huge amount of unforeseen responsibilities.

Interventions are defined as actions performed to bring about change in people (Feldman et al., 2012). By identifying cerebral palsy early and providing early intervention it helps to reduce the developmental delays resulting into an improvement in the quality of life of the children with $\mathrm{CP}$ and reduce the burden of the caregivers. On the other hand, late intervention results into further complications and it delays the parents to understand the condition of the child and how to cope with it. Factors affecting late intervention in Zambia are not well known and so it is paramount to investigate factors affecting late physiotherapy intervention in children with cerebral palsy at the University Teaching Hospital (UTH) in Lusaka, Zambia. CP is the leading cause of disability worldwide and Zambia has its fair share of cases. While attending clinical placement at UTH Children's Hospital in 2017, the researcher noted that most parents/caregivers of children with cerebral palsy started attending physiotherapy late when the children were over one year. When the mothers of the children with $\mathrm{CP}$ were asked why they started attending physiotherapy late, they had little or no information on the developmental milestones of the child and so they waited a little longer for their child to have a good head control or start sitting. If the mother had suspicions that the child was delaying in developing, they were sent back by the doctors who said it was too early to tell if the child had delayed milestones. The nurses on the other hand just encouraged the mothers to feed their children well (give them a balanced diet) and give their child time to grow. Among other things, the mothers also complained about social economic factors like transport expenses. These factors motivated the researcher to carry out a research. Cerebral Palsy is a chronic condition which requires long term management and therefore it is important to identify the factors leading to late physiotherapy intervention, if the children with C.P are to benefit. Late intervention may have implications such as late recovery time and poor quality of life.

The discussion may consist of several sub-chapters. The discussion includes the framework, research methodology, data collection, data processing, analysis and discussion.

\section{Research Methodology}

\subsection{Study Design}

An exploratory study design utilising qualitative methods of data collection was used. The aims of the exploratory study were to establish the facts, explore topics which are relatively unknown, formulate a problem and develop a hypothesis for further study (Babbie \& Mouton, 2001). Although the current study was not used for the development of a hypothesis, the data related to factors contributing to the late physiotherapy intervention of children with cerebral palsy at the University Teaching Hospital, 20172018 was useful to formulate a problem for further study. Furthermore, the researcher attempted to understand the caregivers in terms of their own meaning of their words, and that could not be obtained in a quantitative research method which is one of the 
major distinguishing characteristics of a qualitative research method (De Vos et al., 2002). The study was done in Lusaka, the capital city of Zambia, a country situated in the southern part of Africa with 753,000 square kilometres (UN, 2005). Zambia shares borders with the Democratic Republic of Congo, Tanzania in the north, Malawi and Mozambique in the east, Zimbabwe and Botswana in the south, Angola and Namibia in the west and south west respectively. Lusaka is one of the 10 provinces of Zambia as well as one of the fastest developing cities in Southern Africa with a population of 1.7 million (Zambia Statistic, 2010). The study was conducted at the biggest state funded hospitals of Lusaka the University Teaching Hospital. The researcher chose this site because it's a referral hospital and receive more cerebral palsy patients than others. The researcher has given below some brief description of the selected hospital.

\subsection{Study Population and Sampling Method}

The population of this study included 10 mothers with children aged 0-5 years attending Physiotherapy at University Teaching Hospital 2018. Based on methods of theoretical saturations, a purposive sample of about 10 mothers who attend physiotherapy at UTH, who were willing to participate, was selected. This is in line with Latham (2013) who proposed that 10 participants as a minimum sample for qualitative studies works very well when participants are homogenous. Two focus group discussions were conducted, with each constituting of five participants. This is supported by Gill et al., (2008) who reported that the optimum size for a focus group is five to eight participants (excluding researchers), but focus groups can work successfully with as few as three. Polit and Hungler (2001), and Brink (2006) describe purposive sampling as a method based on the researcher's judgment about subjects that are typical or representative of the phenomenon being studied in cases where the researcher is particularly knowledgeable about the problem. Furthermore, the researcher chose specific hospital to be included in the study because this hospital receives more patients with cerebral palsy illness than others.

\subsection{Data Analysis}

Marshal \& Rossman, (2006) describe data analysis as the procedure that is categorizing, structuring and putting meaning to the mass of collected data. The goal of qualitative data analysis was to produce a detailed and systematic recording of themes and issues addressed in the interview and to link them together under reasonable exhaustive category system. Digital audio- recorded data from the FGDs was transcribed verbatim for each session by the researcher. The researcher read the transcripts several times to familiarize himself and compared with the recorded data as Neuman (2000) suggests. The data was classified systematically by means of coding to identify key factors or issues such as concepts, categories, themes and the relationship between them. The categories led to the development of patterns and themes within the data (Cresswell, 2003).

Contradictions, divergences and convergences were reconciled the point of data interpretation (Moran-Ellis et al., 2006). The data was transcribed by an 
independent person (researcher) for trustworthiness. The researcher sought the supervisor's opinion during the coding process and the themes and patterns to confirm with two or three participants. The researcher endeavored to extract the participants understanding of the issues under question through FGDs and it was subjected to indepth thematic analysis method to resolve the significant themes and subthemes that emerged from the data. In this regards all relevant and necessary documents of the transcripts were assembled together as one through thematic orientation request and lastly the naming of categories was guided by the literature.

\subsection{Ethical Approval and Consent}

Ethical approval to conduct a study was obtained from the University of Zambia School of Health Sciences Research Ethics Committee. Permission was also sought from the study site. In order to enroll participants in the study information sheet was distributed among participant to acquaint them with the study procedures and objective, then participants were allowed to sign consent form after agreeing and they were informed about the freedom to withdraw at any time without any consequences.

\section{Results}

\subsection{Demographics of Participants}

Table 1. Demographic Characteristics of Mothers Analysis

\begin{tabular}{|c|c|c|c|c|c|c|c|}
\hline Code & $\begin{array}{c}\text { Age of } \\
\text { Participant }\end{array}$ & $\begin{array}{l}\text { Marital } \\
\text { Status }\end{array}$ & $\begin{array}{l}\text { Level of } \\
\text { Education }\end{array}$ & $\begin{array}{c}\text { Status of } \\
\text { Employment }\end{array}$ & $\begin{array}{l}\text { Age of } \\
\text { Child } \\
\text { (Yrs) }\end{array}$ & $\begin{array}{c}\text { Sex } \\
\text { Of } \\
\text { Child }\end{array}$ & Type of CP \\
\hline M1 & 46 & Married & Tertiary & Employed & 3 & $M$ & $\begin{array}{l}\text { Spastic } \\
\text { diplegia }\end{array}$ \\
\hline M2 & 32 & Divorced & Primary & Unemployed & 2 & $F$ & $\begin{array}{c}\text { Spastic } \\
\text { quadraplegia }\end{array}$ \\
\hline M3 & 23 & Married & Tertially & Unemployed & 3 & $\mathrm{~F}$ & Diplegia \\
\hline M4 & 37 & Married & None & Unemployed & 1 & $\mathrm{~F}$ & $\begin{array}{l}\text { Spastic } \\
\text { diplegia }\end{array}$ \\
\hline M5 & 21 & Single & Secondary & Unemployed & 2 & $F$ & Athetoid \\
\hline M6 & 41 & Married & None & Unemployed & 2 & M & Triplegia \\
\hline M7 & 19 & Single & Primary & Unemployed & $\begin{array}{c}11 \\
\text { Months }\end{array}$ & $\mathrm{F}$ & $\begin{array}{l}\text { Spastic } \\
\text { diplegia }\end{array}$ \\
\hline M8 & 35 & Divorce & None & Unemployed & 4 & M & $\begin{array}{c}\text { Spastic } \\
\text { Quadriplegia }\end{array}$ \\
\hline M9 & 18 & Married & Secondary & Unemployed & 2 & $\mathrm{~F}$ & Diplegia \\
\hline M10 & 31 & Widow & None & $\begin{array}{c}\text { Self } \\
\text { employed }\end{array}$ & 2 & $\mathrm{~F}$ & Hemiplegia \\
\hline
\end{tabular}

The sample size for this study was 10 which comprised mothers of children with cerebral palsy. The mothers' ages ranged between 18 and 46 years of age. The ages of 
the children ranged between 11 months and 5 years with different types of CP. The mothers' level of education, marital and employment status are indicated in table 1.

\subsection{Emerging Themes from the Focus Group Discussions}

Table 2. shows the 5 themes that emerged from the FGDs. The first four themes addressed the objective which was; to explore factors that contribute to late physiotherapy intervention among children with cerebral palsy 0-5 years attending physiotherapy at U.T.H. The fifth theme addressed the other objective which was; to assess the knowledge of mothers with children between 0-5 years on the role of physiotherapy in cerebral palsy.

Table 2. Emerging themes and categories from the FGDs presented under specific

\begin{tabular}{|c|c|c|}
\hline Specific objective & Themes identified & Subthemes \\
\hline \multirow{4}{*}{$\begin{array}{l}\text { 'To explore factors that } \\
\text { contribute to late } \\
\text { physiotherapy intervention } \\
\text { among children with } \\
\text { cerebral palsy } 0-5 \text { years } \\
\text { attending physiotherapy at } \\
\text { U.T.H' }\end{array}$} & Socio-economic support & $\begin{array}{l}>\text { Social support } \\
>\text { Financial support }\end{array}$ \\
\hline & $\begin{array}{l}\text { Late referral for } \\
\text { physiotherapy }\end{array}$ & $\begin{array}{l}>\text { Doctor's referral } \\
>\text { Self-referral }\end{array}$ \\
\hline & $\begin{array}{l}\text { Caregiver's knowledge } \\
\text { about cerebral palsy }\end{array}$ & $\begin{array}{l}>\text { Lack of education by } \\
\text { clinicians } \\
>\text { Lack of community } \\
\text { sensitization about } \\
\text { cerebral palsy } \\
>\text { Caregiver's age }\end{array}$ \\
\hline & $\begin{array}{l}\text { People's attitude towards } \\
\text { cerebral palsy }\end{array}$ & $\begin{array}{l}>\text { Negative attitude } \\
>\text { Social stigma } \\
>\text { Parent's denial }\end{array}$ \\
\hline $\begin{array}{l}\text { 'To assess the knowledge of } \\
\text { mothers with children } \\
\text { between } 0-5 \text { years on the } \\
\text { role of physiotherapy in } \\
\text { cerebral palsy.' }\end{array}$ & $\begin{array}{l}\text { Care giver's knowledge } \\
\text { about physiotherapy }\end{array}$ & $\begin{array}{l}>\text { Limited community } \\
\text { awareness about } \\
\text { physiotherapy } \\
>\text { Lack of caregiver } \\
\text { education }\end{array}$ \\
\hline
\end{tabular}

\subsection{Factors contributing to late physiotherapy intervention}

Participants narrated their perceptions regarding factors causing late physiotherapy intervention of children with cerebral palsy. These factors were described under themes: Socio-economic support; late referral for Physiotherapy; Caregiver's knowledge about cerebral palsy; and People's attitude towards cerebral palsy. 


\section{Social-Economic Support}

Most participants in this study reported socio-economical support as the main factor leading to late physiotherapy intervention of children with cerebral palsy. Participants revealed that lack of information and assistance from others was one of the reasons why they delayed to engage their children into the physiotherapy rehabilitation process. Thus, in this study two aspects of social economical support were reported, and these were: Social support provided to the parents at home by family and community members; and the financial support that is required for the parent and the child to attend physiotherapy treatment.

\section{Social support}

Most participants deemed social support as a most important characteristic of patient care in Lusaka. Participants revealed that most families lacked the encouragement and advice from other people around to motivate them to continue with treatment. It was explained that most of the participants in this study had poor family support. Some participants reported that they found it difficult to bring their children initially for Physiotherapy treatment because of lack of cooperation in their families. Participants further highlighted that family members were not supportive, and that they keep blaming the mother that it is her fault, she was the cause of problem and she should deal with it alone.

"So family don't pay much attention... they think its my fault, so I should deal with it”. M3

"Family was not very cooperative....we just used to sit...they said you are the one who caused the problem". (M8)

Participants further reported that husbands contributed greatly to delayed physiotherapy intervention that after the child is diagnosed of cerebral palsy they start blaming the wife for it instead of looking for the way forward, so they are always quarrelling about it with their wives. It was further explained that most husbands in Lusaka attributed cerebral palsy to not taking antenatal drugs, so they will be blaming their women for that reason.

\footnotetext{
"Me every day we used to quarrel with my husband, he said am the cause of this." (M1)

"...my husband would even ask me questions like "were you taking ant natal tablets, were you taking malaria tablets, even blood tablets. You just used to sit, you are the one who caused the problem" (M5)
}

Most of the participants further narrated that they were not able to commence Physiotherapy treatment because of lack of family support. One participant also reported that she could not start physiotherapy immediately after being referred because the husband was refusing to come with her to the hospital. It was further explained that some husbands think that only women take their children to the physiotherapy department, so in the cases where the mother is not able to, the child will just be home because the father can't come to the physiotherapy department. 
"I was not too well to start bringing the baby for physiotherapy...my husband refused that we wait until I recover from my sickness" (M7)

"When the time for physiotherapy came I told my husband to take the child with me so that he sees what happens here, but he said "only women go there, have you ever saw a man there before?" So we didn't come" (M10)

The other encounter narrated with regards to poor social support revealed that other participants were not able to commence Physiotherapy because they had no one take care of their homes behind. One participant further explained that she had a small baby, so she found it difficult to bring the child for treatment because there was no one to take care of their homes when they were away to attend treatment.

"... it is like I have two babies. I lack someone to take care of my small baby so that I can bring the child to the hospital." (M9)

\section{Financial Support}

Most participants in this study revealed that lack financial support was one of the factors which influenced late physiotherapy intervention of their children. Some participants in this study explained that they had failed to commence physiotherapy immediately after referral due to lack of money to pay for transport to the hospital. When asked why transport money was a major problem, some participants reported that both them and their husbands were neither employed nor engaged in any business.

"...I had no money to pay for transport to travel to the hospital since my husband is not working or doing any business..." (M5)

"Am not employed and I did not have enough money to start physiotherapy... have to spend about a k100 kwacha per day bring my son here for physiotherapy" (M2)

Some participants reported that they come from very far place away from the hospital and they have to connect two or three vehicles to reach the hospital. Participants reported that they could afford money for physiotherapy treatment but transport was very expensive when they had to attend therapy more than once in a week.

"Paying for physiotherapy treatment is not an issue very much...but transport money is a problem because my husband and I we are not employed." (M6)

Participants indicated that financial considerations and relatedly, transport problems, had a significant impact on late intervention. Support among mothers was associated significantly with adherence to scheduled treatment regimens for their children. It was further indicated that some participants found it expensive to bring their child for treatment every week and that the expenses incurred in bringing the child for treatment was beyond their means.

Other participants reported that children with cerebral palsy require special needs such as dipper, milk and yoghurt, so they prefer using the little money they have on such needs than spending it on transport to the physiotherapy clinic. 
"You know these children require special needs" (M7)

"It is really a challenge managing the baby of such a condition, in terms of buying necessities such as dippers, plus bringing him to the hospital, we couldn't manage to start physiotherapy... it is really a challenge" (M8)

"Other children with cerebral palsy are unable to chew even, they only feed on soft staff such as yoghurt, milk, so it is a challenge" (M3)

\section{Late Referral for Physiotherapy}

Most participants in this study revealed that their children with cerebral palsy delayed to engage into physiotherapy rehabilitation because of late referrals either from the doctors or by the caregivers themselves. Hence subthemes encompassed in this theme are: doctor's referral and self-referral to the physiotherapy department.

\section{Doctor's Referral}

Most participants in this study disclosed that the transfer of care of a child with cerebral palsy from a doctor to a physiotherapist is usually delayed. Most participants reported that they were delayed to start physiotherapy by their doctors who would tell them to wait until the baby is six months and or above. It was further reported that even when some participants noticed that there was a problem with their babies, doctors would still tell them to wait until the baby is six months before coming up with a diagnosis and further interventions.

"So at six months that's when the doctor said you have to start physiotherapy" (M2)

"Just wait for her when she is about six months plus...After six months I went there again and that's when they advised me to do physiotherapy then" (M5)

"After a month we went there and they told us to come back when he was six months old. After six months we went there and that's when they told us about physiotherapy" (M9)

"Meanwhile I noticed the problem at three months because there were no much activities in the baby, but I was told to start physiotherapy when he is six months plus by the doctor." (M3)

Participants further wondered why doctors even after noticing the problem early would still tell you to wait until the baby is six months and above to commence Physiotherapy. Other participants revealed that doctors were able to tell whether a child has sustained a brain injury after birth based on the presentation of the baby, but they still waited until the baby was six months to refer them for physiotherapy. One participant further highlighted that birth complications such jaundice and not crying immediately after birth are directly related to brain damage, but doctors despite understanding that they still told them to wait.

"When he was born he did not cry at birth so the doctor explained that because of that he will be slow to develop...but I was told to start coming for physiotherapy at six" (M4) 
"He had jaundice...they explained that it causes brain injury...So when he was one month plus had taken him to the hospital for reveal and they said I should take him back at six months" (M10)

"the baby didn't cry at birth...I condemn them...despite knowing that the baby has a problem, they discharged me early in the morning without even taking some time to observe the baby and was not even given any reveal" (M8)

Other participants reported that they knew about physiotherapy, and that it's the only thing which could help their babies, but they could not start physiotherapy because they were still waiting upon their doctors to refer them to the physiotherapy department, hence the delay. Most participants further reported that it is better for the doctors to be referring the children with cerebral palsy to the physiotherapists earlier than six months, or just after noticing the developmental delays in a baby. One participant revealed that physiotherapist attend to babies with different conditions as young as a month, so why refer them at six months. Participant in this study further reported that they believed that if their children were referred early for physiotherapy they would have been doing far much better by now.

"Have been wondering why they did not refer me to physiotherapy so early because I have noticed that you even attend to babies as young as a month, so I think if my baby was referred early he would have improved by now." (M7)

"If they were referring us just after noticing the problem it was going to be better unlike referring us when the baby is six months." (M2)

The other encounters revealed were poor communication between the doctor and the caregiver upon referral. Some participants reported that they delayed to start physiotherapy because their doctor did not explain how physiotherapy was going to help out with this condition, they were just told to go physiotherapy without telling them what it does, so they ended up hesitating to commence physiotherapy immediately after being referred. Participants reported that some doctors have a poor attitude towards caregiver education, and that they only came to understand cerebral palsy after physiotherapists explained to them.

"The doctor never told me anything about what physiotherapy does...so I hesitated to start."(M9)

"The doctor just said that we come to physiotherapy...we did not know what was happening."(M3)

"...it was a physiotherapist who explained for me not a Doctor" (M1)

\section{Self-Referral}

This study also encountered other participants who delayed to engage their children with cerebral palsy to physiotherapy despite referring themselves to the physiotherapy department without having to see the doctor or anyone else. The participants reported that the main reason for the delay was because they were waiting on the baby to improve. Other participants further disclosed that people around them 
would tell them to give it some time that other babies delay to develop even when there is nothing wrong with them.

"He was a premature...so we thought that's how he is that he was going to improve later." (M6)

"People around used to tell me to wait...give it a little bit of time to improve...but he was not improving." (M10)

"I noticed the problem at three months because he was not able to roll in bed, at 4 months he was not even trying to sit. At one year four months I just referred myself to the physiotherapist..." (M9)

\section{Lack of education by clinicians}

Most participants reported that they lacked knowledge about cerebral palsy because they were not educated about it by their doctors, doctors would just mention that their baby has cerebral palsy and refer them to the physiotherapy department without even explaining what it is. The other participant also revealed that when she asked the doctor what he meant by cerebral palsy, the doctor just said that the baby has a weak trunk and told her to just start physiotherapy. It was further narrated that some doctors are too casual and lazy to educate the caregivers about these conditions.

"Like for me they did not explain well, I didn't even know that this child will have a problem. I was not told anything; I just saw that the baby was slow as compared to other babies." (M7)

"Oh if the doctor had explained what it is...it's just that they were a little bit casual and lazy I think" (M5)

"...but then there they said that she has a week trunk and I should start physiotherapy" (M4)

Participants also revealed that during the antenatal clinic most of the nurses also don't sensitize expecting mothers about other complications of pregnancy such as jaundice and their resulting conditions such as cerebral palsy. Other Participants explained that they learnt quiet a lot of things at antenatal clinic except for complications such as baby not crying immediately after birth and jaundice, and how these complications can lead to conditions such as cerebral palsy. The other participant explained that after giving birth the baby did not cry immediately but the nurse could not even sensitize her about the possible outcomes, otherwise she would have been vigilant and or begin physiotherapy as soon as she noticed early signs of the problem.

"I used to come for antenatal and they would teach a lot of staff but I don't remember any of them mention jaundice and how its effects or cause cerebral palsy.”(M9)

"I never knew anything about jaundice, even my sister I was with didn't know anything about it. Otherwise I noticed it early, only if I knew it...I saw it about two weeks ago...I wish I was taught about it at antenatal" (M6) 
“...baby didn't cry at birth...I condemn them...despite knowing that the baby has a problem, they discharged me early in the morning without even taking some time to sensitize me about the possible outcomes of that." (M8)

The other encounter narrated with regards to the lack of knowledge about cerebral palsy among caregivers was the lack of caregiver education by the physiotherapists handling their children. One participant reported that at her first encounter to the physiotherapy department, she was not educated about cerebral palsy, she was only seeing the physiotherapist turning and rotating the baby without explaining what was wrong with it. The other participant thought the physiotherapist would explain after treatment but instead she was only told to go back home and come the next day. It was further highlighted by some participants that because of lack of explanation about cerebral palsy, physiotherapy never used to make any sense to the caregivers.

"They would just lift the baby and rotate him, stretch him a little bit...without explain the problem." (M1)

"...then said go home and come next day...It never used to make sense for me." (M4)

"Sometimes they will just ask you, hold your baby, do this and that, that's all...not even educating you about the baby's sickness" (M7)

\section{Lack of community sensitization about cerebral palsy}

Most participants reported that health workers engaged in disseminating information within Lusaka, and or making the community aware of and being responsive to certain diseases or situations never talk about cerebral palsy. Participants explained that there are a lot of children with cerebral palsy in the community but because of lack of sensitization most people do not know what to do with them, resulting either to late physiotherapy intervention or no intervention at all and that some their conditions end up worsening.

"There is no community sensitization about conditions like cerebral palsy" (M2)

"We have seen babies in the community with weak upper limbs or other condition but because you don't know what to do it worsens." (M6)

It was further highlighted by most participants that because of lack of community sensitization about cerebral palsy people's attitude towards families or children with cerebral palsy was not good. Participants explained that people would have different opinions about cerebral palsy, with others thinking its just laziness. One participant further elaborated that she gave birth together with a neighbor, and people in the community would wonder a lot why her baby was not developing while the neighbor's baby was growing so well. Participants explained that negative attitude from the community towards family of a child with cerebral palsy contributes to late physiotherapy intervention. It was also explained that as a result of that other families end up hiding or locking up their babies and wait for them to die instead of taking them for physiotherapy. 
"The attitude of the community is not good, they don't know what cerebral palsy is" (M10)

"They even start asking you why your child is not developing, they sometimes start thinking maybe its just lazy, and their comments have a negative impact" (M4)

"...gave birth together with someone nearby...there baby was progressing well while mine is not" (M1)

"You find the baby has weakness and they just lock it up and wait for it to die. Others even kill their babies with disabilities" (M3)

Some participants further highlighted that because of lack of community sensitization about cerebral palsy, most people in the community belief a child with cerebral palsy has just been bewitched.

"This has come as a result of witchcraft...nothing else" (M6)

Participants further revealed that as a result of attributing cerebral palsy to witchcraft the treatment which was opted for by most people in the community was traditional medicines. It was explained that most caregivers thought somebody did that to them, that if it came from the roots, they should also go back to the roots. Participants revealed that it was so difficulty to start physiotherapy early because they really believed it had everything to do with witchcraft.

"I was told to try a lot of traditional staffs." (M9)

"Somebody did this to me, so if it came from the roots, I should also go back to the roots." (M7)

The other traditional remedies which lead to late physiotherapy intervention as disclosed by some participants were; stretching the neck of the baby with an ax, doing tattoos on the child's body, and also massaging the baby with a dirt mother's underwear.

"My auntie tells me to do some tattoos on his legs and other traditional medicines." (M4)

"... hit the baby with an ax on the neck...to stretch the neck and wait for change to start." (M6)

"Also that massaging him with my dirt underwear helps cure the weakness." (M2)

\section{Social Stigma}

Most Participants linked late physiotherapy intervention with cerebral palsy children with caregiver's tendency to withdraw their children from the public. Participants explained that some caregivers did not want their babies with cerebral palsy to be seen by other people in the community, they would rather keep their child indoors to avoid negative responses from the people around, hence delay to start physiotherapy.

"You find that someone would rather be indoors not want to be seen by people out there" (M5) 
Participants further revealed that other people in the community have labelled children with cerebral palsy as "disabled', and that if you are a mother of a child with cerebral palsy people will call you the 'mother of that disabled child'. It was explained that such labelling from the community has a negative impact as it leads to social isolation. Some participants also added that some people in the community don't call these children by their names, they would rather say a 'disabled child'.

"People around call your child disabled...they also call you mother of a disabled child not by your names" (M7)

"People were asking me that "who are you going to be leaving your disabled child with?" (M1)

\section{Discussion}

The ages of the mothers ranged between 18 and 46 years with a mean age of 32 years. This study recruited a wider age group because factors experienced by younger mothers may not necessarily be the same as factors experienced by older mothers. Most studies on factors experienced by mothers of children with CP use mothers of a wide age group (Resch et al, 2010; Gona, mun'gala-Odera, Newton \& Hartley, 2010). Factors experienced by younger mothers mainly include; worry about the condition of their children, marriage, education and employment whereas older mothers are mainly affected with financial and physical health challenges (Sen \& Yurtsever, 2007). It has also been reported that mothers of different age groups view disability differently (Borst, 2010).

In this study, the level of education among the participating mothers ranged between uneducated and tertiary education. Four (4) of the participating mothers had no form of education, 2 of the mothers had their primary education, 2 had their secondary education and only 2 had their tertiary education. From the above data it is evident that the majority of the participating mothers had no form of education. Regarding employment, 1 of the mothers was in formal employment, 1 was selfemployed whereas 8 of the participating mothers were unemployed. A study by Resch et al (2010) regarding challenges experienced by mothers of children with disabilities, revealed that majority of the mothers in their study were from low income class. In the same study, majority of the mothers had less than high school education, only 3 of out of a sample of 20 mothers had high school education and another 3 had a college education. Another study in Kalifi, Kenya showed similar findings on mothers of children with CP who had poor education and were not in employment (Gona, Mung'ala-Odera, Newton \& Hartley, 2010).

This study revealed four dimensions of factors that contributed towards late physiotherapy intervention among children with CP attending physiotherapy at UTH, and these were: Socio-economic support; late referral for physiotherapy; Caregiver's knowledge about CP; and People's attitude towards CP. 
The findings in this study reported that lack of socio-economical support contributed towards late physiotherapy intervention among children with CP at UTH. The study highlighted that lack of social support provided to the parents at home by family and community members in form of encouragements, advice and motivation contributed sincerely towards delayed commencement of the physiotherapy rehabilitation process. This is in line with the findings by Singogo et al., (2012), in the study on the challenges experienced by mothers of children with cerebral palsy in Zambia. Singogo and colleagues reported that because of lack of social support from their friends, family and the community, some mothers could not commence the habilitation process of their children.

The study revealed that the physiotherapy habilitation process of children with $\mathrm{CP}$ was also delayed by family members of these children who spent much time blaming the mothers for the child's condition instead of just completing a referral program and their retention in treatment. This is synonymous with finding by Singogo et al.,(2012) who reported that families believe if a mother gives birth to a child with disabilities, they should be blamed as giving birth to a child with disabilities is seen as failure to follow certain antenatal instructions. However, there has been little research done on negative attitudes towards mothers and their children with cerebral palsy in Africa. The few studies done in Uganda, Ghana, Zimbabwe and Zambia had similar findings to that of the current study regarding negative attitudes of communities towards children with disabilities (Masasa, 2005; Hartley et al., 2004; Bwana and Kyohere, 2001).

The establishment in this study that not having someone to take care of other children at home influenced the parents bringing the child for treatment corresponds with the finding of Biwott (2014). In his study on caregivers' adherence to occupational therapy, he revealed that $80 \%$ of the parents indicated that they did not have someone at home to take care of their other children. This was reported as one of the factors that hindered them from bringing the child for treatment.

The findings of this study suggested that lack of financial support that was required for the parent and the child to attend physiotherapy treatment was a factor which hindered many parents from engaging their children with physiotherapy in Lusaka. The study reported that most caregivers lacked transport money to come to the hospital. This finding is in line with other studies which reported that poverty and resource constraints are the known factors for nonaccess of health and rehabilitation services in developing countries (kroll et al., 2006; Simkiss et al., 2011; Patel et al., 2012; Mlenzana et al., 2013). Financial constraint and difficulty in transportation as the barriers for rehabilitation of neurological disability has been reported from other part of India as well (Kumar and Gupta 2012; Srivastava et al., 2014).

This study further highlighted that financial challenges among caregivers was mainly due to lack of employment. Studies have shown that most mothers of children with CP are not in employment (Borst, 2010; Gary and Edward, 2009; Talley and Crews, 
2007). Other reasons cited in literature for lack of employment among mothers include; Failure of mothers to combine employment and their care giving roles, poor health, duration of caring episodes and willingness of employers to accommodate mothers' caring needs(Gray \& Edward, 2009). These findings are different from those of the mothers in this study as they were not employed mainly due to their low education levels and the lack of employment opportunities in Zambia. Unemployment deprives mothers of an income and sound financial standing in societies. When families do not have enough income, fundamental prerequisites for good health are difficult to obtain. It is therefore important to empower mothers with skills that will enable them to be selfsufficient.

The study found a significant association between compliance to referral advice and transport costs indicating that parents who found transportation costs to hospital very expensive delayed to attend treatment than those who found transport cheap. This result also supports earlier findings by Kim and Tellen (2004), in Korea where it was found that the child's dental care were less likely to follow up on the treatment at the dentists. Similarly, Kilter, Salgado, Moulton, Neito, Contreras et al (2003) in a study on factors constrains adherence to referral advice for severely ill children in Ecuador found that high transport costs to health centers were significant constraints that prevented mothers from completing a referral program and their retention in treatment.

Since most of these parents who participated in this study were unemployed it is likely that they were financially dependent on their spouses or relatives and had no direct control over the financial resources that were required to meet transport costs and other necessary expenses.

The findings in this study revealed that most children with CP where brought late to the physiotherapy department due to late referral either by the doctors or by caregivers. Most mothers of children with CP interviewed stated that they delayed to begin physiotherapy because their doctors told them to wait until their babies were six months and /or above to begin physiotherapy. This finding is synonymous with the finding by Simpamba et al., (2010) who reported that doctors contributed to late physiotherapy intervention as they told mothers to wait until the child is old enough.

This study reported that some of the medical personnel who attended to children with CP initially gave them a wrong diagnosis. Some of the wrong diagnosis given to the mothers included; trunk weakness, and flaccid paralysis. This, the mothers thought delayed them in implementing the right treatment and therapies for their children. This is in line with the finding by Singogo et al., (2015) who reported in the study on challenges experienced by mothers of children with cerebral palsy that most of the participating mothers claimed to have received a wrong diagnosis for their children with cerebral palsy. Irrespective of the fact that mild cases of CP are difficult to diagnose in the first few months or years, some studies have shown that in most cases physicians fail to give the right diagnosis (Huang, Kellett and St John, 2010; George, Vickers, Wilkes 
\& Barton, 2007). If they do, they fail to give adequate explanation to the affected individuals.

The study also reported of the poor referral system which only encompassed of a doctor, and never utilized other specialties to have contributed towards late referrals. This observation provides support to the notion that poor referral system that does not fully utilize the expertise available within the health care system is one of the main factors that influence the access to rehab services in India (Chiluba et al.,2019). It is imperative that extra efforts are made to sensitize the medical community about the need of timely referral for physiotherapy to CP children.

A delayed diagnosis or wrong diagnostic makes the mothers despair. All they want to know is what is wrong with their children on time. In this study, some of the mothers failed to trust healthcare professionals as they failed to give a right diagnosis for their children. The mothers felt alone as their suspicions and concerns were not confirmed and they felt that some of the treatments administered to their children were inappropriate and delayed the right treatment. A study that looked into the diagnosis of children with CP found that "delays in effective diagnosis not only increased mothers' mistrust and dissatisfaction with physicians' knowledge and skills, but fuels their hopelessness and aggravated anger about receiving a better prognosis" (Ashwal et al, 2004). These findings are similar to those of the current study. It is a possibility that some of the mothers were not aware that the diagnosis of CP may take long. The healthcare professionals attending to mothers must explain to the mothers the complexities involved in diagnosis the condition of $\mathrm{CP}$ rather than sending them away without any explanation or diagnosis.

The findings of this study suggested that mothers of children with CP delayed to begin the physiotherapy rehabilitation process because they lacked familiarity, awareness, and understanding of physiotherapy roles in cerebral palsy. This finding was synonymous with Stanton et al., (2007) who reported in their study that there was deficit in the knowledge among the caregivers about the physiotherapy management of children with disabilities, hence did not utilize the service.

The study reported lack of community awareness about physiotherapy to be the major factor causing limited knowledge among community residents. This finding associating lack of community awareness about physiotherapy with poor service utility corresponds with the finding by Sinha et al., (2017). Sinha and colleagues revealed an association between awareness of physiotherapy roles and the degree of service utilization by the community, thus reported limited awareness to be the cause of poor service utilization.

The study further reported that most caregiver only got to know about physiotherapy after being referred there. This finding clearly indicated the low levels of awareness of the role that physiotherapy plays in relation to the management of 
children with disabilities. This finding corresponds with Padhyegurjar and Padhyegurjar (2012) who reported that in urban slum of Mumbai $87.1 \%$ attribute the lack of knowledge of rehabilitative services as the reason for not taking treatment. Study of Srivastava et al (2014) conducted in Mau district of Uttar Pradesh reported unawareness as the main reason for not availing rehabilitation services.

Mander, (2006) reported that awareness of disability and role of physiotherapy has been found to be essential in developing knowledge and skills for self-help, care, management, and decision-making among family members of children with disability. On the other hand, Harikrishna and Kamalamba (2017), in a similar study, concluded that there was need to educate the general public in Sri Lanka about Physiotherapy both as a therapeutic modality and as a prospective career pathway and the role it plays in managing disabilities that occur both in children and adults (Chuni, 2018).

The study further reported lack of caregiver education by the clinicians (doctors, nurses) about physiotherapy to have contributed towards late physiotherapy intervention among children with CP. This finding is synonymous with other researchers who echoed that, to improve compliance to treatment healthcare providers should give patients and caregivers enough education about the treatment and disease (Gascon et al., 2004; lihara et al., 2004; Kaona et al., 2004; Ponnusankar et al., 2004; Seo and Min 2005). Prior study by Stein et al., (2003) highlighted that education regarding rehabilitation should begin in the acute hospital setting and continue throughout the rehabilitation process, however, the current study reported of lack of caregiver education in the hospital setting.

Previous studies providing family with physiotherapy knowledge have shown some benefit for caregivers in terms of satisfaction with practical information provision (Kalra et al., 2004; Chiluba \& Muke, 2019) emotional support (Lincoln, 2003), mood (Kalra et al., 2004) and improved quality of life (Mant, 2000). As current study highlights, it is imperative for the doctors to learn how to teach the caregivers of children with CP about some basic physiotherapy roles in order to complement their effort on commencing the habilitation process.

This study further attributed doctors' attitude towards caregivers' education to limited knowledge about physiotherapy. This finding is supported by Stanton et al (2007) who assessed resident physician's knowledge of physiotherapy and concluded that there was deficit in the knowledge among the residents especially about the treatment modalities used by the physiotherapists in managing children with disabilities. The study by Shemjaz et al., (2016) clearly states that there is a lack of awareness and knowledge among medical interns about physical therapy. On the other hand, Harikrishna and Kamalamba (2017), in a similar study, concluded that there was need to educate the general public in Sri Lanka about Physiotherapy both as a therapeutic modality and as a prospective career pathway and the role it plays in managing disabilities that occur both in children and adults. 
The study also revealed that due to inadequate knowledge about physiotherapy, some doctors refer physiotherapy as 'exercise' and this brought a lot of doubt among caregivers as to how 'exercise' could help their children's condition, hence decided not to utilize the service. So there is a need of educating the future medical professionals about the physiotherapy thereby achieving a better patient care.

\section{Conclusion}

The present study sought to explore the perceptions of mothers towards factors contributing to late physiotherapy intervention in children with CP. A diversity of factors that led to delayed intervention was highlighted, and these included; lack of social and financial support, late referrals, limited knowledge about $C P$, negative attitude, social stigma and denial. If healthcare professionals and the government do not recognize these factors experienced by the mothers, the physical, psychological and general wellbeing of the mothers will deteriorate and their children due to lack of financial assistant and assistance with assistive devices will have more physical limitations and disability will be over represented. Rehabilitation professionals should be aware of the factors that impact mothers both positively and negatively in order to implement effective rehabilitation programs.

\section{References}

Ashwal, S., Russman, B.S., Blasco, P.A., Miller, G., Sandler, A., Shevell, M. \& Stevenson, R. (2004). Practice parameter: diagnostic assessment of the child with cerebral palsy. Child Neurology, 72(5) 126-131.

Babbie E, \& Mouton J. (2001). The practice of social research. Cape Town: Oxford University Press. Baeck, London.

Biwott LC (2014). Factors influencing cerebral palsy caregivers' adherence to occupational therapy in Usain Gishu County: a case of moi teaching and referral hospital.

Borst, J.B. (2010). Caregivers of seriously disabled children and their relationship issues on the labor market. Population Research and Policy Review, 24, 467-488

Brehaut JC, Kohen DE, Raina P, Walter SD, Russell DJ, Swinton M, O"Donnell M and Rosenbaum P. (2004). The health of primary caregivers of children with cerebral palsy: how does it compare with that of mothers of other Canadian caregivers? Pediatrics 114(2): 182

Bwana, O. \& Kyohere, O. (2001). Parent's role in CBR: A Participatory Strategy in Africa. Centre for International Child Health, 51, 117-126.

Chiluba, B. and Moyo, G. (2017). Caring for a cerebral palsy child: a caregiver"s perspective at the University Teaching Hospital, Zambia. BMC Research Notes, 10(1).

Chiluba, BC and Muke, N. (2019). Barriers to Health Care for Disabled People: A Review of the Literature from Low Income Countries. Indonesian Journal of Disability Studies (IJDS). 2019: Vol. 6(2): PP 210 - 214. 
Chiluba et al. (2019). An Assessment of the Health Literacy Among Deaf People in Kapiri Mposhi District of Zambia. Indonesian Journal of Disability Studies (IJDS). Vol. 6(2): PP 128-132.

Chuni C, Chiluba BC, Mwango M, Nkandu EM, Shula H. (2018). An Exploration of the Knowledge of Informal Caregivers on Ageing Related Health Conditions at Matero and Chawama Old People's Homes, Zambia. International Journal of Neurologic Physical Therapy. Vol. 4, No. 1, 2018, pp. 1-6. doi: 10.11648/j.ijnpt.20180401.11

Creswell JM. (2003). Qualitative, Quantitative \& Mixed Method (2nd ed.). Los Angeles: Sage.

De Vos AS, Strydom H, Fouche CB, \& Delport CSL. (2002). Research at grass Roots: 2nd edition. Pretoria: Van Schaik.

Feldman DB, Dreher DE. (2012).Can hope be changed in 90 minutes?Testing the efficacy of a single-session goal-pursuit intervention for colledge students. Journal of happiness studies.13 (4): 745-759.

Gascon JJ, Sanchez-Ortuno M, Llor B, et al., 2004. Treatment Compliance in Hypertension Study Group. Why hypertensive patients do not comply with the treatment: results from a qualitative study. Fam Pract, 21:125-30.

Gary, M., \& Edwards, B. (2009). Determinants of the labour force status of female carers. Australian Journal of Labour Economics, 12(1), 5-20.

Gona, J.K., Mung'ala-Odera, V., Newton, C.R. \& Hartly, S. (2010). Caring for children with disabilities in Kalifi, Kenya. Rural and Remote Health, 47, 447-455.

Harikrishna, R. and Kamalamba, H. (2017). Awareness and attitude towards physiotherapy among higher secondary students: a pilot survey study. International Journal of Physiotherapy and Research, 5(1), pp.1846-1851.

Huang, Y.P., Kellett, U.M \& St John, W (2010). Cerebral palsy: experiences of mothers after learning their child's diagnosis. Australia, Blackwell.

Kalra L, Evans A, Perez I, Melbourn A, Patel A Knapp M, \& Donaldson N. (2004). Training carers of stroke patients: Randomised controlled trial. British Medical Journal, 328, 1099-1103.

Kaona FA, Tuba M, Siziya S, et al. (2004). An assessment of factors contributing to treatment adherence and knowledge of TB transmission among patients on TB treatment. BMC Public Health, 29:68.

Kim, Y. O and Tellen, S. (2004). Predictors of Utilization of Oral health services by children of low-income families in the United States: Beliefs, Costs: or provides? Taehan Kanho Hakhoe (Abstract). 34(8): 1460-1467.

Kroll T, Jones GC, Kehn M, Neri MT. (2006). Barriers and strategies affecting the utilisation of primary preventive services for people with physical disabilities: A qualitative inquiry. Health Soc Care Community; 14:284-93.

Kumar H, Gupta N. (2012). Neurological disorders and barriers for neurological rehabilitation in rural areas in Uttar Pradesh: A cross-sectional study. J Neurosci Rural Pract ;3:12-6. 
Latham JR. (2013). A framework for leading the transformation to performance excellence part I: CEO perspectives on forces, facilitators, and strategic leadership systems. Quality Management Journal, 20(2), 22.

Lincoln NB, Francis VM, Lilley SA, Sharma JC \& Summerfield M. (2003). Evalua- tion of a stroke family. Stroke Journal 34:116-121.

Mander H, Rao V. (2006). An Agenda for Caring, Intervention for Marginalized Groups. New Delhi: Voluntary Health Association of India.

Mant J, Carter J, Wade DT \& Winner S. (2000). Family support for stroke: A random-ised controlled trial. Lancet, 356, 808-813.

Masasa, T. (2005). Knowledge of, beliefs about and attitudes towards disability: Implications for healthcare professionals. South African Family Practice, 47 (7), 4044.

Marshall C \& Rossman GB. (2006). Designing Qualitative Research.

Neuman W., (2000). Social Research Methods. Qualitative and Quantitative Methods. Boston. Ally and Bacon.

Padhyegurjar MS, Padhyegurjar SB. (2012). Factors affecting treatment seeking behaviour of individuals with locomotor disabilies. Natl J Med Res; 2:145-8.

Patel SK, Ladusingh L. (2009). Age Pattern of Onset of Disability and Treatment Seeking Behaviour of Disabled Persons in India; Available from: http://www.princeton.edu/download.aspx?submissionld=91173.

Ponnusankar S, Surulivelrajan M, Anandamoorthy N, et al., (2004). Assessment of impact of medication counseling on patients' medication knowledge and compliance in an outpatient clinic in South India. Patient Educ Couns, 54:55-60.

Resch, J.A., Mireles, G., Benz, M.R., Curenwelge, C., Patterson, R. \& Zhang, D. (2010). Giving parents a voice: Qualitative study of the challenges experienced by parents of children with disabilities. Rehabilitative Psychology, 55 (2): 139-150

Seo MA, Min SK., 2005. Development of a structural model explaining medication compliance of persons with schizophrenia. Yonsei Med J, 46:331-40.

Shemjaz, A. M., Anuj, H., \& Saddam, M. H. (2016). Awareness and knowledge of physical therapy among medical interns - a pilot study. International Journal of Physiotherapy, 3(2), 170-176.

Simkiss DE, Blackburn CM, Mukoro FO, Read JM, Spencer NJ. (2011). Childhood disability and socio-economic circumstances in low and middle income countries: Systematic review. BMC Pediatr; 11:119.

Simpamba, M. Moyo, G. Nkandu, M. and Munthali, C. (2010). Common causes of cerebral palsy and factors contributing to late physiotherapy intervention in children with cerebral palsy at the university teaching hospital, Zambia Christensen DB. Drugtaking compliance: a review and synthesis. Health Serv Res. 1978; 13:171-87

Singogo, C., Mweshi, M. \& Rhoda, A. (2015). 'Challenges experienced by mothers caring for children with cerebral palsy in Zambia', South African Journal of Physiotherapy 71(1), Art. \#274, 6 pages. 
Stanton, P., Fox, F., Frangos, K., Hoover, D. and Spilecki, G. (2007). Assessment of Resident Physicians' Knowledge of Physical Therapy. Physical Therapy, 65(1), pp.27-30.

Stein J, Shafqat S, Doherty D, Frates EP, Furie KL. (2003). Patient knowledge and expectations for functional recovery after stroke. Am J Phys Med Rehabil; 82:591596.

Talley, R. C., \& Crews, J. E. (2007). Framing the public health of caregiving. American Journal of Public Health, 97(2), 224-228.

UN. (2005). International Human right instrument. Central Statistical Office 2000. Census of population, Lusaka-Zambia. 